\title{
Assessment of chemical properties of tropical peatland soil in Malaysia oil palm plantation
}

\begin{abstract}
The chemical assessment of the peatland in oil palm plantation in South Selangor Peatland Swamp in Malaysia were evaluated in this study. Soil samples were obtained from fifteen (15) different locations within the study area at three different depths of $0.5 \mathrm{~m}, 1.5 \mathrm{~m}$, and 2.5 $\mathrm{m}$ in three replicates at each depth, using peat auger between March and July, 2013 during the secondary maximum rainfall. Parameters evaluated in soil analysis included - $\mathrm{pH}$, moisture content, carbon, nitrogen, sulphur and heavy metals such as manganese, zinc, iron, copper, and phosphorus. Heavy metals were determined using the double acid extraction method while carbon, nitrogen, and sulphur was determined using Trumac CNS Analyzer. From the $\mathrm{pH}$ values, the soil close to the surface is more acidic with a mean $\mathrm{pH}$ of 3.36 and standard error of 0.15 . The mean values of the moisture contents were $363.54 \%$ with SEM of 27.01 and $154.56 \%$ with SEM of 54.64 at $0.5 \mathrm{~m}$ and $2.5 \mathrm{~m}$ depths respectively. Carbon, had the highest value of $44.27 \%$ at $0.5 \mathrm{~m}$, nitrogen, $0.36 \%$, sulphur, $0.15 \%$ and heavy metals like manganese, iron, and copper, except zinc, and phosphorus had their mean values either increasing or decreasing with soil depth. Soil carbon was observed to decrease with depth unlike nitrogen and soil $\mathrm{pH}$. All the parameters were observed to either decrease or increase with depth which shows their spatial distribution across the soil mass. This assessment of the tropical peatland soils chemistry has helped in appraising the important roles played by intact peatlands in overall global environmental sustainability.
\end{abstract}

Keyword: Chemical properties; Tropical peatland; Oil palms cultivation; Soil quality; Greenhouse gases 